\title{
An Artificial Stock Market Based on Soft Control Theory
}

\author{
Pan Fuchen 1, 2, , Li Lin ${ }^{3}$ \\ ${ }^{1}$ College of Science, Dalian Ocean University, Dalian, China \\ ${ }^{2}$ College of Basic Education, Dalian University of Finance and Economics, Dalian, China \\ ${ }^{3}$ Department of Technology, Dalian Radio and TV University, Dalian, China
}

Email address:

pancf@dlou.edu.cn (Pan Fuchen), litiptop@163.com (Li Lin)

${ }^{*}$ Corresponding author

\section{To cite this article:}

Pan Fuchen, Li Lin. An Artificial Stock Market Based on Soft Control Theory. International Journal of Economics, Finance and Management Sciences. Vol. 6, No. 2, 2018, pp. 54-59. doi: 10.11648/j.ijefm.20180602.13

Received: March 8, 2018; Accepted: April 18, 2018; Published: April 27, 2018

\begin{abstract}
In this study, we consider the simple but typical artificial stock market model proposed by LeBaron, B. et al.: each trader makes decision by maximizing the same utility function. We constructed a multi-agents artificial market model and investigated the effect of control traders among traders on price shock transfer from one asset to the whole market. The model is composed of two sorts of asset: price stocks and its underlying stocks. Our simulation featured two types of agent: control trader and ordinary traders. Control trader, who owns enough wealth, can intervene in the trading behavior of the group by applying the trading rule: trade when the stock price deviates from preset value. The traders in the artificial stock market reproduce their stylized facts related mainly to information asymmetry and herd behavior, which reduces the volatility of the stock market. The implications for market rules are discussed. From simulations of various trading strategies of control traders, we found the stock price can be controlled by control traders with certain strategies. The simulation results demonstrate the effectiveness of the method.
\end{abstract}

Keywords: Soft Control, Artificial Stock Market, Control Trader, Stock Returns

\section{Introduction}

Artificial stock markets are models of real stock markets, designed with the aim to study market dynamics. In agent-based artificial stock markets agents are used to represent traders on a market. The idea to use intelligent agents for studying market dynamics originates from the agent-based computational economics approach, the computational study of economies modeled as evolving systems of autonomous interacting agents [1]. Since there is a large variety of real stock markets and trading strategies, researchers have proposed different frameworks which can be configured to support multiple artificial stock markets [2-6]. Kovaleva and Iori highlight that endogenous restriction of displayed quote depth, by means of iceberg orders, improve liquidity, moderate volatility, balance the limit order-book and enhance price [7]. Cowboying stock market herds with robot traders is dicussed [8] Computer simulation technology is used to obtain micro-interpretation behind macroscopic heteromorphism of financial market, creating a new field of experimental finance discovery [9]. Investment and output at the firm level are affected by individual net worth in the presence of a financial friction [10]. Xu et al. studied multiple assets with spot-futures arbitrageurs in an attempt to reproduce the statistical properties of real Chinese markets [11]. Takuma Torii et al. constructed a multi-asset artificial market model and investigated the effect of arbitrage trading among multiple assets on price shock transfer from one asset to the whole market [12]. Wang and Wang showed a stochastic time effective function neural network with principal component analysis for time series prediction [13]. Scholars are using some methods which were not common earlier, for instance text-mining was also used in stock prediction problem [14].

Clustering of volatility and fat tails of returns distributions are stylized facts of real markets. Furthermore, bubble is a mainly characteristic in most markets owning to speculator's non-rationable investment, which is disgusted by ordinary traders (OT). How to avoid more bubble in the market? Some tactics, such as enhancement of transaction tax and interest 
rate of bank, have been used. Contrary, it's important to arouse the investment desire in the pessimistic market condition.

Soft control, proposed by Hanjing etc [15], has been applied to collective behavior of mul-agents.

In mul-agents systems, one way of the control can be achieved by using some leader agents. We differentiate between two classes of leader-controlled swarms models. One is called the apparent leader, the other is called the hidden leaders. The distinction lies in whether the leader agents can be identified by other agents in swarms. Hidden leader agents are more protected than apparent leaders.

In apparent leaders case, all ordinary agents must know the presence of the leader agents. Accordingly, the dynamics of the ordinary agents must incorporate the role of the leader agents. The result is a heterogeneous swarm, where ordinary agents simultaneously follow their dynamics. The leader agents influence the dynamics of ordinary agents. Therefore, by controlling the leader agents, we can control the warms.

In hidden case, some leaders infiltrated into the mul-agents system. The infiltrated agents, who called shill agents, are recognized by the other agents as ordinary agents. The mul-agents system is controlled by adjusting the dynamics of these shill agents. Because the ordinary agents are not aware of being infiltrated, we call this type of control as soft control. The influence of the shill agents is not explicitly included in the dynamic of each agent. Shills control the other agents only by taking advantage of the agents' interactions [16].

In this paper, soft control is used to stabilize the stock market. A way to control the market without changing the rules of the existing traders is to add one (or a few) special trader which can be controlled. Therefore its behavior does not necessarily obey the rules as the ordinary traders do. The special trader is the only controlled part of the system. We call the special trader as control trader (CT).

The rest of this paper is organized as follows: an artificial stock market model with control traders is proposed in section 2 , including architecture of market, evolution algorithm, control strategy. Section 3 is some cases for soft control in artificial stock market. Some concluding remarks are given in Section 4.

\section{Soft Control on Artificial Stock Market}

Artificial stock markets are models design to capture essential properties of real stock markets in order to reproduce, analyze or understand market dynamics with computational experiments [17]. Since the first artificial stock market was developed in the early nineties at the Santa-Fe Institute [18]. A good and recent overview of ASMs can be found in [19].

\subsection{Market Architecture}

In this section, we plan to propose a new architecture. This architecture rests on CT to interact with OT, which we think is a key to stabilize market.

Figure1 gives the market architecture represented. The left of Figure 1 is the market as a single object. At the right of Figure1, it is a population of interacting heterogeneous agents including CT. We define ith trader's neighbors who directly interact with ith trader. In the neighborhood, the information (knowledge) about the market is openly distributed among all traders. Nothing is kept secret. CT acts the same strategy as OTs to make decision before they accept new control command. But, once instructions are obtained, control traders will use particular tactics to achieve expected result.

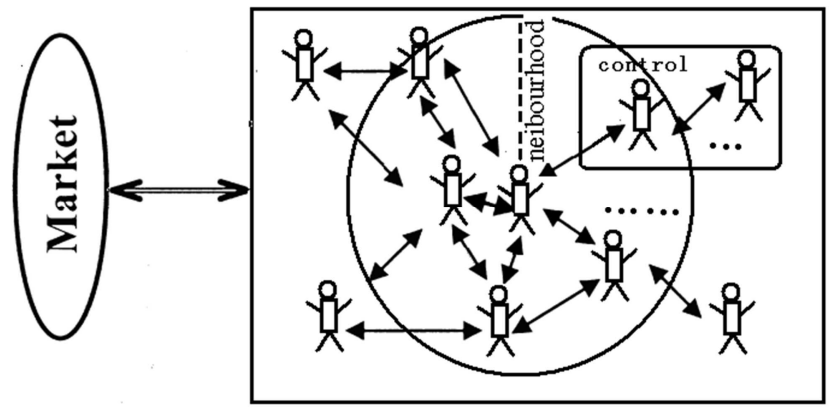

Figure 1. Artificial stock market architecture with control traders.

A single risky asset is considered in the market. A trader can divide his/her wealth between this risky asset and a riskless asset ("cash"). At each period a trader takes a position (buy/sell/hold). Shares are bought in fixed size lots of one share.

Resources are finite and hence traders have portfolio limits associated with either zero cash or zero stock. Short selling is not permitted.

The Santa Fe Artificial Stock Market, as described in [20], served as a starting point for the model described in this paper. In their model, financial agents are recursive in nature as they form beliefs and expectations about the market on the basis of what they believe will be the other agents' expectations. A constant absolute risk aversion (CARA) utility function is recommended,

$$
\mathrm{U}\left(\mathrm{W}_{\mathrm{i}, \mathrm{t}}\right)=-\exp \left(-\lambda \mathrm{W}_{\mathrm{i}, \mathrm{t}}\right)
$$

where $W_{i, t}$ is the wealth of trader $i$ at time period $t$, and $\lambda$ is the degree of relative risk aversion. At each point in time, each trader has two ways to keep her wealth,

$$
\mathrm{W}_{\mathrm{i}, \mathrm{t}}=\mathrm{M}_{\mathrm{i}, \mathrm{t}}+\mathrm{P}_{\mathrm{t}} \mathrm{h}_{\mathrm{i}, \mathrm{t}}
$$

where $M_{i, t}$ and $h_{i, t}$ denotes the money and shares of the stock held by trader $i$ at time $t$. Given this portfolio $\left(M_{i, t}, h_{i, t}\right)$, a trader's total wealth $W_{i, t+l}$ is thus

$$
W_{i, t+1}=(1+r) M_{i, t}+h_{i, t}\left(P_{t+1}+D_{t+1}\right)
$$

where $P_{t}$ is the price of the stock at $t$ and $\mathrm{D}_{\mathrm{t}}$ is per-share cash dividends paid by the companies issuing the stocks. $D_{t}$ can follow a stochastic process not known to traders. $r$ is the riskless interest rate. 


$$
\mathrm{E}_{\mathrm{i}, \mathrm{t}}\left(\mathrm{U}\left(\mathrm{W}_{\mathrm{i}, \mathrm{t}+1}\right)\right)=\mathrm{E}\left(-\exp \left(-\lambda \mathrm{W}_{\mathrm{i}, \mathrm{t}+1} \mid \mathrm{I}_{\mathrm{i}, \mathrm{t}}\right)\right)
$$

where $E_{i, t}(\cdot)$ is the expected utility function of trader i regarding the conditional expectation at $t+1$ given his information up to $t$ ( the information set $I_{i, t}$ ), which will be to myopically maximize the one period.

It is well known that under CARA utility and Gaussian distribution for forecasts, trader i's desire demand, $\mathrm{h}_{\mathrm{i}, \mathrm{t}+1}^{*}$, for holding shares of risky asset is linear in the expected excess return:

$$
\mathrm{h}_{\mathrm{i}, \mathrm{t}}^{*}=\frac{\mathrm{E}_{\mathrm{i}, \mathrm{t}}\left(\mathrm{P}_{\mathrm{t}+1}+\mathrm{D}_{\mathrm{t}+1}\right)-(1+\mathrm{r}) \mathrm{P}_{\mathrm{t}}}{\lambda \sigma_{\mathrm{i}, \mathrm{t}}^{2}}
$$

where $\sigma_{i, t}^{2}$ is the conditional variance of $P_{t+1}+D_{t+1}$ given $I_{i, t}$.

After each period price is updated exogenously via a supply/demand type law as follow:

$$
P_{t+1}=P_{t}\left[1+\eta\left(\left(B_{t}^{o}-O_{t}^{o}\right)+\left(B_{t}^{c}-O_{t}^{c}\right)\right)\right]
$$

In this equation, which is common to many ASMs, $P_{t}$ is price at $\mathrm{t}$ and $\mathrm{B}_{\mathrm{t}}^{\mathrm{o}}$ and $\mathrm{O}_{\mathrm{t}}^{\mathrm{c}}$ are the aggregate demand and supply for OTs at $\mathrm{t}$, and $\mathrm{B}_{\mathrm{t}}^{\mathrm{o}}$ and $\mathrm{O}_{\mathrm{t}}^{\mathrm{c}}$ are the aggregate demand and supply for CTs at $\mathrm{t}$, while $\eta$ is a parameter. Large values of $\eta$ lead to large price oscillations while small values lead to slow price adjustments.

\subsection{Control Rule for Control Trader}

Bubble of the stock market is dangerous. How to avoid it? In this case, obviously, we can use some control means, such as increasing interest rate of bank to change to the ratio of investment in the bank. But can we solve it by soft control? If some traders can be controlled, we can design some special trading strategies to stabilize market. In this section, we will study a simple but non-trivial related problem.

The problem we consider here is: for a group of $n$ ordinary traders with initial money and shares of the stock $\left(M_{i, 0}, h_{i, 0}\right)$, $1 \leq \mathrm{i} \leq \mathrm{n}$, and only a control trader with $\left(M_{0,0}, h_{0,0}\right)$, what is the trading strategy for CT, so that overbidding or underbidding can't happen?

Suppose the trading rules about the traders are known as over-mentioned. Suppose also that the state information in the neighborhood of the traders is observable at any time step. Now we propose an effective control law for CT which is defined as follows:

$$
h_{0, t+1}=\left\{\begin{array}{cc}
h_{0, t}+b_{0, t}, & \text { if } P_{f}>(1+\delta) P_{t} \\
h_{0, t}, & \text { if } P_{f}=(1+\delta) P_{t} \\
h_{0, t}-o_{0, t}, & \text { if } P_{f}<(1+\delta) P_{t}
\end{array}\right.
$$

where $\mathrm{P}_{\mathrm{f}}$ is the fundamental price, $\delta \in(0,1)$ is a constant that measures the current price deviation. $b_{0, t}\left(o_{0, t}\right)$ is share of purchase (sale) at t for CT defined by:

$$
\begin{aligned}
& \mathrm{b}_{0, \mathrm{t}}=\left\{\begin{array}{cc}
0, & \text { if } \mathrm{B}_{\mathrm{t}}^{\mathrm{o}}>\mathrm{O}_{\mathrm{t}}^{\mathrm{o}} \\
\operatorname{int}\left(\frac{\mathrm{M}_{0, \mathrm{t}}}{\mathrm{p}_{\mathrm{t}}}\right) \times 0.1, & \text { if } \mathrm{B}_{\mathrm{t}}^{\mathrm{o}}=\mathrm{O}_{\mathrm{t}}^{\mathrm{o}} \\
\min \left\{\left(\mathrm{O}_{\mathrm{t}}^{\mathrm{o}}-\mathrm{B}_{\mathrm{t}}^{\mathrm{o}}\right)(1+\varepsilon), \frac{\mathrm{M}_{0, \mathrm{t}}}{\mathrm{p}_{\mathrm{t}}}\right\}, & \text { if } \mathrm{B}_{\mathrm{t}}^{\mathrm{o}}<\mathrm{O}_{\mathrm{t}}^{\mathrm{o}}
\end{array}\right. \\
& \mathrm{o}_{0, \mathrm{t}}=\left\{\begin{array}{cc}
0, & \text { if } \mathrm{B}_{\mathrm{t}}^{\mathrm{o}}<\mathrm{O}_{\mathrm{t}}^{\mathrm{o}} \\
\mathrm{h}_{0, \mathrm{t}} \times 0.1, & \text { if } \mathrm{B}_{\mathrm{t}}^{\mathrm{o}}=\mathrm{O}_{\mathrm{t}}^{\mathrm{o}} \\
\min \left\{\left(\mathrm{B}_{\mathrm{t}}^{\mathrm{o}}-\mathrm{O}_{\mathrm{t}}^{\mathrm{o}}\right)(1+\varepsilon), \mathrm{h}_{0, \mathrm{t}}\right\} & \text { if } \mathrm{B}_{\mathrm{t}}^{\mathrm{o}}>\mathrm{O}_{\mathrm{t}}^{\mathrm{o}}
\end{array}\right.
\end{aligned}
$$

where $\varepsilon>0$ is a parameter. Large values of $\varepsilon$ leads to fast convergence while small value leads to slow convergence.

Suppose the CT owns enough money and shares to stability market, then we have

Theorem 1. Above hypothesis is satisfied, for any $\mathrm{n} \geq 2$, and any initial money and shares of the stock (Mi, 0 , hi, 0), the update rule (5)-(6) and the soft control law defined by (7), (8), (9) will lead to stability market, i.e. $\left|\frac{\mathrm{P}_{\mathrm{f}}-\mathrm{P}_{\mathrm{t}}}{\mathrm{P}_{\mathrm{t}}}\right| \leq \delta$

Proof.

1) If $\left|\frac{P_{f}-P_{t}}{P_{t}}\right| \leq \delta$, theorem has been proved.

2) If $\left|\frac{\mathrm{P}_{\mathrm{f}}-\mathrm{P}_{\mathrm{t}}}{\mathrm{P}_{\mathrm{t}}}\right|>\delta$, i.e. $\mathrm{P}_{\mathrm{f}}>\mathrm{P}_{\mathrm{t}}(1+\delta)$ or $\mathrm{P}_{\mathrm{f}}<\mathrm{P}_{\mathrm{t}}(1-\delta)$, we discuss it as follows: If $\mathrm{P}_{\mathrm{f}}>\mathrm{P}_{\mathrm{t}}(1+\delta)$, which implies that the market is pessimism. To active the traders, the rule (8) is used. Let $\Delta_{t+1}=P_{t+1}-P_{t}$, then

$$
\begin{aligned}
\Delta_{\mathrm{t}+1} & =\mathrm{P}_{\mathrm{t}+1}-\mathrm{P}_{\mathrm{t}} \\
& =\mathrm{P}_{\mathrm{t}}\left[1+\eta\left(\left(\mathrm{B}_{\mathrm{t}}^{\mathrm{o}}-\mathrm{O}_{\mathrm{t}}^{\mathrm{o}}\right)+\left(\mathrm{B}_{\mathrm{t}}^{\mathrm{c}}-\mathrm{O}_{\mathrm{t}}^{\mathrm{c}}\right)\right)\right]-\mathrm{P}_{\mathrm{t}} \\
& =\mathrm{P}_{\mathrm{t}} \eta\left[\left(\mathrm{B}_{\mathrm{t}}^{\mathrm{o}}-\mathrm{O}_{\mathrm{t}}^{o}\right)+\mathrm{b}_{0, \mathrm{t}}\right] \\
& =\left\{\begin{array}{cc}
\eta\left(\mathrm{B}_{\mathrm{t}}^{\mathrm{o}}-\mathrm{O}_{\mathrm{t}}^{o}\right) \mathrm{P}_{\mathrm{t}}>0, & \text { if } \mathrm{B}_{\mathrm{t}}^{\mathrm{o}}>\mathrm{O}_{\mathrm{t}}^{o} \\
\eta\left(\operatorname{int}\left(\frac{\mathrm{M}_{0, \mathrm{t}}}{\mathrm{P}_{\mathrm{t}}}\right)\right) \mathrm{P}_{\mathrm{T}} \times 0.1>0, & \text { if } \mathrm{B}_{\mathrm{t}}^{o}=\mathrm{O}_{\mathrm{t}}^{o} \\
\eta \varepsilon\left(\mathrm{O}_{\mathrm{t}}^{o}-\mathrm{B}_{\mathrm{t}}^{o}\right) \mathrm{P}_{\mathrm{t}}>0, & \text { if } \mathrm{B}_{\mathrm{t}}^{\mathrm{o}}<\mathrm{O}_{\mathrm{t}}^{o}
\end{array}\right.
\end{aligned}
$$

From above, we get $\Delta_{t+1}>0$, which implies that $\mathrm{P}_{\mathrm{t}+1}>\mathrm{P}_{\mathrm{t}}$. Because the current price will ascend with passing t, we can get $\left|\frac{\mathrm{P}_{\mathrm{f}}-\mathrm{P}_{\mathrm{t}^{*}}}{\mathrm{P}_{\mathrm{t}^{*}}}\right| \leq \delta$ for some $\mathrm{t}^{*}$. For $\mathrm{P}_{\mathrm{f}}<\mathrm{P}_{\mathrm{t}}(1-\delta)$, we can get similar result using the same method above. This completes the proof of Theorem 1 .

It's noted that it's necessary for CT owning enough money and shares, which can guarantee market stability. Though CT without enough money and shares can adjust the market more 
or less, the result maybe can't be satisfied.

\subsection{Learning Mechanism}

In this section, we consider the learning mechanism for ordinary traders excluding control trader. In order to introduce the concept of learning we consider "copycat" traders [21]. Copycats observe the success of different strategies in the neighborhood and copy the most successful one, updating their expectations periodically in the presence of new information. For example, a copycat might copy that trader that has the portfolio with highest observed Sharpe ratio, or the trader with highest daily returns over a certain period.

\section{Simulation Results}

In this section several simulations have been performed using the system. We present some results of a simulation of 1000 days with 50 ordinary traders and one control trader. In this configuration, traders are endowed with a fixed supply of cash and there is no addition or subtraction except those due to trading. We analyzed two cases first trading no control trader and then introducing a control trader in the other case. $E_{i, t}\left(P_{t+1}+D_{t+1}\right)$ and $\sigma_{i, t}^{2}$ are selected with three parameters $\theta_{1}, \theta_{2}, \theta_{3}$ [22]. Table 1 is an example of the specification of the control parameters to evolve model.

Table 1. Parameters of the artificial stock market.

\begin{tabular}{ll}
\hline parameter & Value \\
\hline Number of OTs & 50 \\
Number of CT & 1 \\
parameters $\theta_{1}, \theta_{2}, \theta_{3}$ & $\theta_{1}=0.5, \theta_{2}=0.001, \theta_{3}=0.01$ \\
degree of RRA $\lambda$ & 0.5 \\
Initial money supply per OT & $\$ 100$ \\
Initial money supply per CT & $\$ 5000$ \\
Shares of the stock per OT & 10 \\
Shares of the stock per CT & 100 \\
Interest rate (r) & 0.1 \\
Stochastic process $\left(D_{t}\right)$ & IID $\sim \mathrm{U}(0.99,2.01)$ \\
$\eta$ & 0.05 \\
$\mathrm{P}_{\mathrm{f}}, \mathrm{P}_{0}$ & $\mathrm{P}_{\mathrm{f}}=\mathrm{P}_{0}=7$ \\
$\delta$ & 0.3 \\
$\varepsilon$ & 0.05 \\
Number of periods & 1000 days \\
\hline
\end{tabular}

A typical comparison about price is shown in Figure 2. The price trend without $\mathrm{CT}$ is seen on the top (a) and adjust curve by introducing $\mathrm{CT}$ at the bottom (b). The region among two blue dashed lines indicates expect price limit. We can see from Figure 2 that soft control is an effective approach to reduce the price bubble. Figure 3 gives the respective return series.

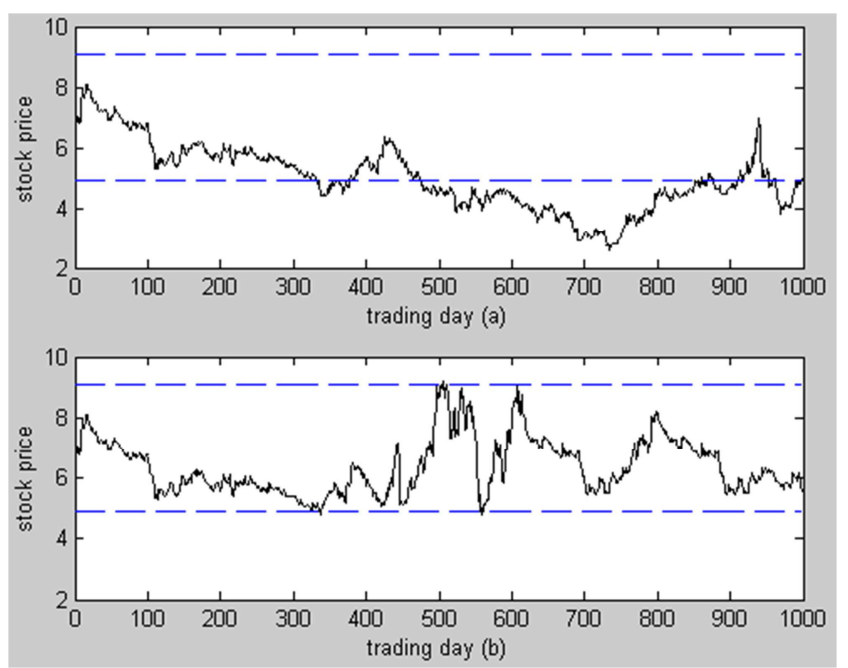

Figure 2. A typical price comparison no CT (a) and with a CT (b).

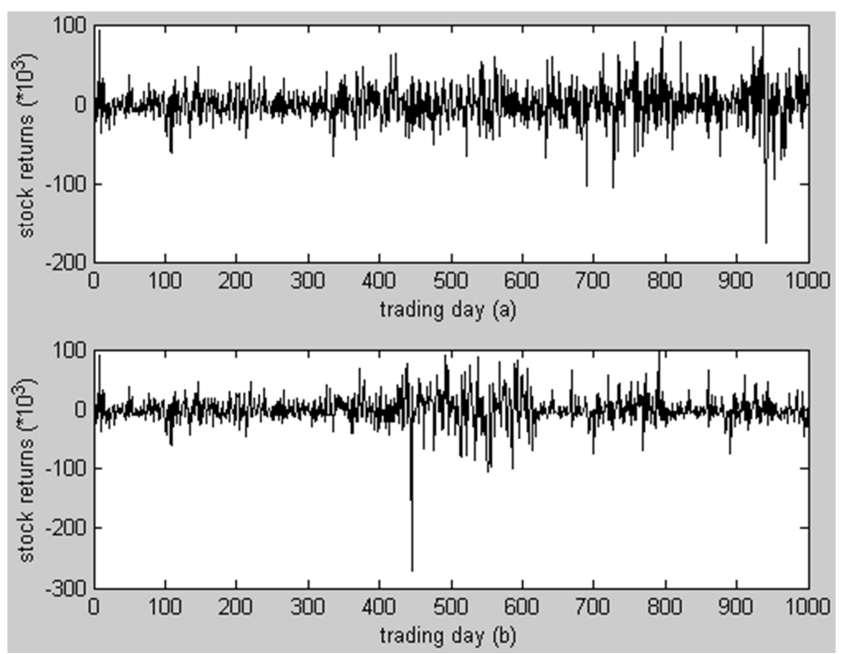

Figure 3. Return series no CT (a) and with a CT (b).

To understand the effects of soft control, we first examine how market volatility $\left(\mathrm{P}_{\mathrm{V}}\right)$ and price distortion $\left(\mathrm{P}_{\mathrm{D}}\right)$ change. The market volatility and the price distortion of a simulation run are defined as [23]:

$$
\begin{gathered}
P_{V}=\frac{100}{N-1} \sum_{t=1}^{N}\left|\frac{P_{t}-P_{t-1}}{P_{t-1}}\right| \\
P_{D}=\frac{100}{N} \sum_{t=1}^{N}\left|\frac{P_{t}-P_{f}}{P_{f}}\right|
\end{gathered}
$$

The price distortion measures the degree of price deviation from the fundamental price. Figure 4, which presents the volatility (a) and distortion (b) under different cases with passing trading days. The distortion on the bottom of the pictures shows the results obtained in the market. It is clear that, soft control, which can stability the stock price, is effective in the artificial stock market. 

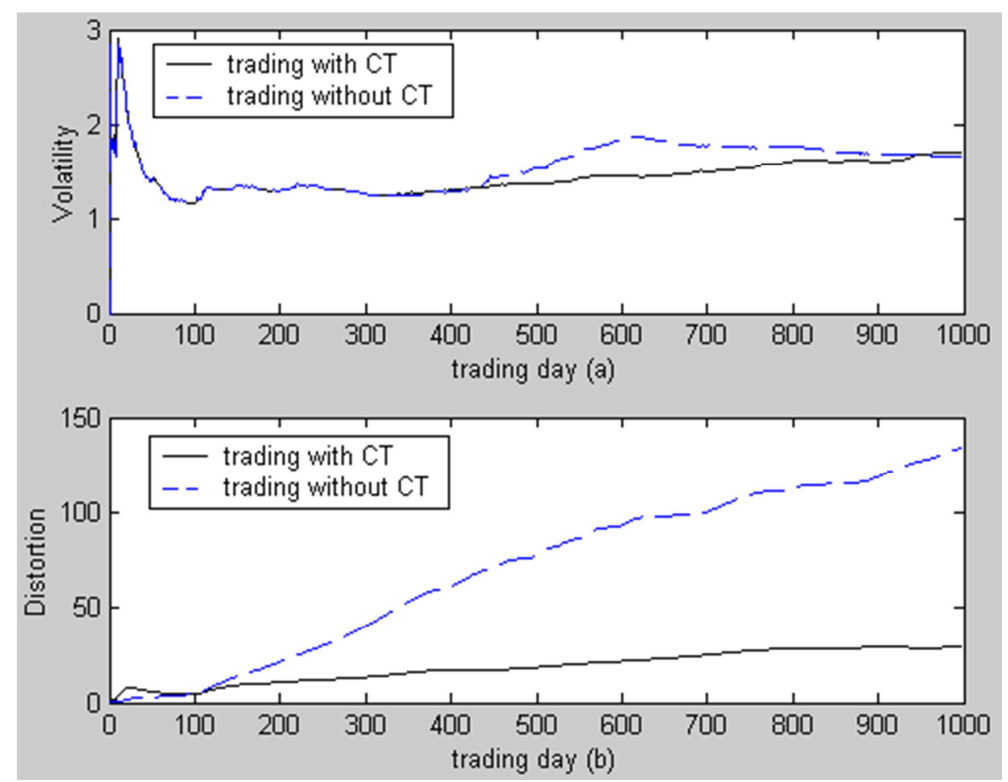

Figure 4. The volatility (a) and distortion (b) under different cases with passing trading days.

\section{Conclusion}

The microcosmic architecture of complex finance systems is the basic content that we concerned and studied in this paper. How we control or intervene in a artificial stock market without changing the trading rules of the existing traders is an important issue. The idea of soft control is used, and a control trader owning enough wealth is introduced to adjust the current price. Control strategy for CT is proposed. Some simulations reinforce our theory.

\section{References}

[1] Leigh Tesfatsion. Introduction to the special issue on agent-based computational economics. Journal of Economic Dynamics and Control, 2001, (25), pp:281-293.

[2] Derveeuw, J. Beaufils, B. Brandouy, O. and Mathieu, P., Testing double auction as a component within a generic market model architecture, In Artificial Economics (AE07). Springer (2007).

[3] LeBaron, B. Agent based computational finance: suggested readings and early research. Journal of Economic Dynamics and Control, 2000, 24, pp: 679-702.

[4] LeBaron, B. A builder's guide to agent-based financial markets. Quantitative Finance, 2001, 1, pp: 254-261.

[5] Westerhoff, F.. The use of agent-based financial market models to test the effectiveness of regulatory policies. Journal of Economics and Statistics, 2008, 228, pp: 195-227.

[6] Galimberti, J. K., \& Moura, M. L. Improving the reliability of real-time output gap estimates using survey forecasts. International Journal of Forecasting, 2016, 32 (2), pp: 358373 .

[7] Kovaleva, P., \& Iori, G.. The impact of reduced pre-trade transparency regimes on market quality. Journal of Economic Dynamics and Control, 2015, 57, pp: 145-162.
[8] Jaqueson K. Galimberti, Nicolas Suhadolnik, Sergio Da Silva. Cowboying stock market herds with robot traders. Computational economics, 2017, 50, pp: 393-423.

[9] Zhou Qingyuan, Luo Juan. The service quality evaluation of ecologic economy systems using simulation computing. Computer systems science and engineering, 2016, 31 (6), pp: 453-460.

[10] Assenza T, Delli Gatti D, Grazzini J, 2015. Emergent dynamics of a macroeconomic agent based model with capital and credit. Journal of economic dynamics and control. 50, pp: 5-28.

[11] Xu HC, Zhang W, Xiong X, Zhou WX. An agent-based computational model for china's stock market and stock index futures market. Mathematical problems in engineering, 2014 Article ID: 563912.

[12] Takuma Torii, Kiyoshi Izumi, Kenta Yamada. Shock transfer by arbitrage trading: analysis using multi-asset artificial market. Evolut Inst Econ Rev, 2015, 12, pp: 395-412.

[13] [13] Wang, J., Wang, J. Forecasting stock market indexes using principle component analysis and stochastic time effective neural networks. Neurocomputing, 2015, 156, pp: 68-78.

[14] de Fortuny, E. J., De Smedt, T., Martens, D., Daelemans, W.. Evaluating and understanding textbased stock price prediction models. Inf. Process. Manag, 2014, 50, pp: 426-441.

[15] Jing Han, Ming Li and Lei Guo. Soft control on collective behavior of a group of autonomous agents by a shill agent. Journal of systems science and complexity, 2006, (19), pp: 54-62.

[16] Guillaume Sartoretti, Leader-based versus soft control of multi-agent swarms, Artificial Life Robotics, 2016, 21, pp: 302-307.

[17] Derveeuw, J. Beaufils, B. Brandouy, O. and Mathieu, P. Testing double auction as a component within a generic market model architecture, In Artificial Economics (AE07), 2007, Springer.

[18] Palmer, r., w. Arthur, j. Holland, b. Lebaron, and p. Tayler. Artificial Economic Life: A Simple Model of a Stockmarket Physica D, 1994, 75, pp: 264-274. 
[19] Boer, K. Agent-Based Simulation of Financial Markets A Modular, Continuous-Time Approach. PhD thesis, Erasmus University Rotterdam, UK (2008).

[20] Arthur W. B., Holland J. H., LeBaron B., Palmer R., Tayler P.. Asset Pricing Under Endogenous Expectations in an Artificial Stock Market, The Economy as an Evolving Complex System, Addison-Wesley, 1997, pp:15-44.

[21] Gordillo, J. L., Stephens, C. R. Analysis of financial markets with the artificial agent-based model - NNCP. Proceedings of ENC01. INEGI, Mexico, 2001, pp: 251-263.
[22] Shu-Heng Chen, Chia-Hsuan Yeh. Evolving traders and the business school with genetic programming: A new architecture of the agent-based artificial stock market. Journal of Economic Dynamics \& Control, 2001, 25, pp. 363-393.

[23] Westerhoff, F. Speculative markets and the effectiveness of price limits. Journal of Economic Dynamics and Control 28, 493-508. G. Eason, B. Noble, and I. N. Sneddon, "On certain integrals of Lipschitz-Hankel type involving products of Bessel functions," Phil. Trans. Roy. Soc. London, 2003, vol. A247, pp: 529-551. 